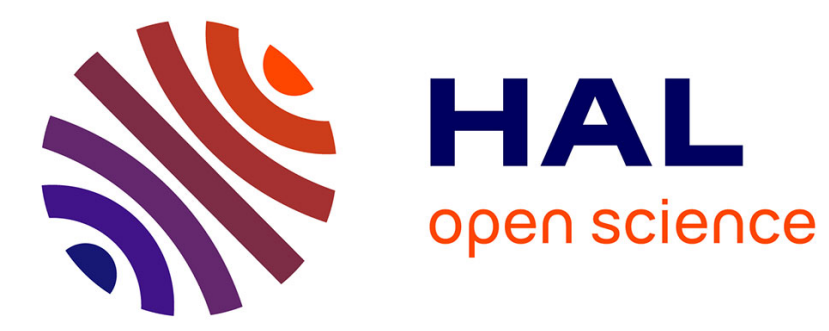

\title{
Energy straggling of heavy ions in thin foils
}

\author{
J.M. Freeman, C.J. Sofield, N.E.B. Cowern, J.P. Mason, R.J. Petty
}

\section{To cite this version:}

J.M. Freeman, C.J. Sofield, N.E.B. Cowern, J.P. Mason, R.J. Petty. Energy straggling of heavy ions in thin foils. Revue de Physique Appliquée, 1977, 12 (10), pp.1539-1542. 10.1051/rphysap:0197700120100153900 . jpa-00244363

\section{HAL Id: jpa-00244363 https://hal.science/jpa-00244363}

Submitted on 1 Jan 1977

HAL is a multi-disciplinary open access archive for the deposit and dissemination of scientific research documents, whether they are published or not. The documents may come from teaching and research institutions in France or abroad, or from public or private research centers.
L'archive ouverte pluridisciplinaire HAL, est destinée au dépôt et à la diffusion de documents scientifiques de niveau recherche, publiés ou non, émanant des établissements d'enseignement et de recherche français ou étrangers, des laboratoires publics ou privés. 


\title{
ENERGY STRAGGLING OF HEAVY IONS IN THIN FOILS
}

\author{
J. M. FREEMAN, C. J. SOFIELD, N. E. B. COWERN \\ J. P. MASON and R. J. PETTY (*) \\ Nuclear Physics Division, AERE, Harwell, \\ Oxon., England
}

\begin{abstract}
Résumé. - La dispersion énergétique des faisceaux d'ions lourds, aux énergies tandem, qui traversent des feuilles minces, a été étudiée au moyen d'ions de masse allant jusqu'à $A=35$. Les expériences ont permis de conclure que l'échange de charge des ions dans la feuille produit un grand effet sur la dispersion énergétique. Des inhomogénéités dans l'épaisseur de la feuille peuvent aussi provoquer des contributions significatives.

L'extrapolation, à partir des observations, pour une feuille de stripping uniforme, dans un accélérateur tandem, suggère que l'énergie doit avoir une dispersion de l'ordre de quelques dixièmes d'un pour cent de l'énergie du faisceau. Cependant, des grandes inhomogénéités dans l'épaisseur de la feuille peuvent détériorer la résolution énergétique du faisceau.
\end{abstract}

\begin{abstract}
The energy straggling of heavy ion beams at tandem energies, passing through thin foils, has been studied with ions of mass up to $A=35$. Charge exchange in the foils has been found to have a considerable effect on the energy spread. Thickness non-uniformities in the foils can also make significant contributions.

Extrapolation of the observations to the case of a uniform carbon stripper foil in a tandem accelerator suggests energy straggling of the order a few tenths per cent of the beam energy. However, large non-uniformities in the foil could appreciably worsen the beam resolution.
\end{abstract}

This paper is concerned with some of the effects produced on heavy ion beams at Tandem energies on their passage through a thin solid foil.

Because of the statistical nature of the collisions and charge-changing processes which take place inside the solid, an initially monoenergetic, parallel beam of ions emerges from a foil with a distribution in angular direction, a distribution of charges (except for very light ions which may be fully stripped) and a distribution in energy about a mean corresponding to the average energy lost in the foil. Experimental information on this energy straggling is sparse, sometimes contradictory and showing large discrepencies with established theory.

We distinguish three distinct ways in which experimentally observed energy straggling may arise :

1. $a$ FluCtuations in COLlisional eXCitation OF TARGET ATOMS. - For ions of a given velocity and constant charge $Z$ (equal to the atomic number for a fully stripped ion), the average energy loss in a given thin foil of uniform thickness $\Delta x$ is, according to basic theory :

$$
\Delta E=K Z^{2} \Delta x
$$

(*) Present address : Physics Department, University of Melbourne, Vic. Australia. and the standard deviation $\sigma$ of the energy distribution about the average value is given by :

$$
\sigma^{2}=K^{\prime} Z^{2} \Delta x
$$

where $K$ and $K^{\prime}$ are constants in the given conditions.

For partially stripped ions with a charge-state distribution $F(q)$ in the solid, the ions on average have a charge $q$ for a total distance $F(q) \Delta x$ in the foil, so that their energy loss in this mode is

$$
(\Delta E)_{q}=K q^{2} F(q) \Delta x
$$

with corresponding $\left(\sigma^{2}\right)_{q}$. Summing over $q$, the total energy loss and straggling are then predicted to be as in equation (1) and (2) above with $Z^{2}=q^{2}$, the mean square charge, or effective charge squared, in the solid.

1. $b$ Charge-EXChange Straggling. - The calculation above assumes that all the ions behave the same as regards the time they spend in their respective charge states in the foil. In fact, as Vollmer [1] has pointed out, there are fluctuations in these times, since the charge-exchange is also a statistical process. For example, following an individual ion which enters the foil with a charge state $q$, its passage through the foil might be as indicated in figure 1. For another ion the distribution amongst the various charge states would 
be different and the summed total energy loss would be different, even when the ions were assumed to lose the average amount of collisional energy between each charge-changing collision.

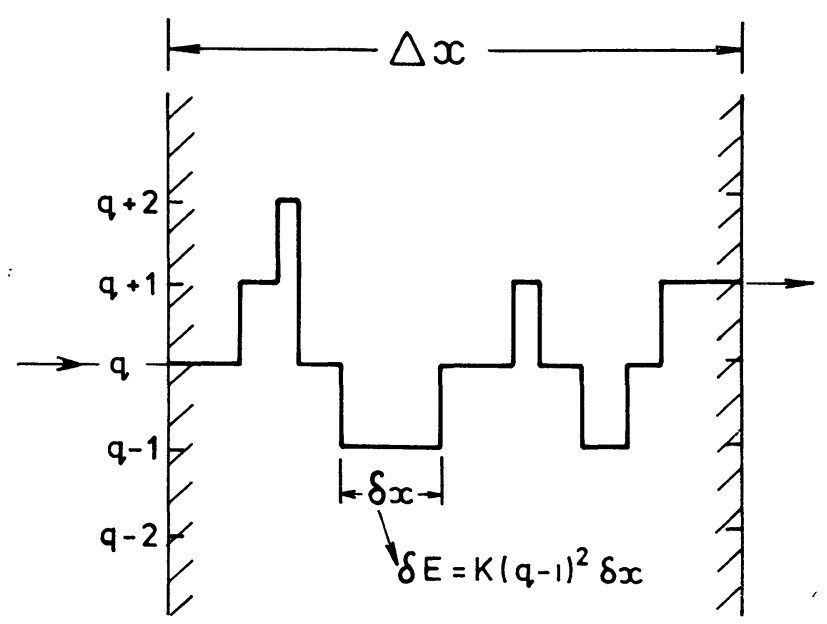

FIG. 1. - Possible sequence of charge-changing events for an individual ion passing through a thin foil.

If the charge-changing cross-sections were all known, Monte-Carlo calculations could be performed to built up on this basis a predicted energy distribution of the emergent ions. The charge-exchange straggling thus calculated would then have to be added in quadrature to the collisional straggling corresponding to the mean square charge, to give the total energy straggling.

1. c FOIL NON-UNIFORMITY. - If the foil thickness over the area covered by the ion beam varies by $\pm y \%$, say, then clearly this percentage of the mean energy loss in the foil will appear as an additional energy spread in the emergent beam.

2. Experimental Investigations. - For our experiments, foils were chosen in the thickness range 100 to several hundred $\mu \mathrm{g} / \mathrm{cm}^{2}$, to allow reasonably accurate straggling measurements and $\mathrm{Al}$ was selected as the material because of the ease of making foils and because some anomalous results have been reported for $\mathrm{Al}$ in the literature.

The ion beams were detected with and without a foil being inserted, so that the mean energy loss was determined and the energy straggling was measured in terms of the full width at half maximum (FWHM) of the straggled distribution with subtraction in quadrature of the FWHM of the unstraggled distribution. A silicon surface barrier detector was used in some cases and in others, particularly for the heavier ions which caused detector damage, a broad-range Buechner spectrograph with photographic plate detection was used.

Straggling measurements using fully-stripped $\alpha$ particles at $5.5 \mathrm{MeV}$ are shown in figure 2 for a range of foil thicknesses expressed in terms of energy loss.
The squares represent measurements using commercially rolled $\mathrm{Al}$ foils and are consistent with some published work [2]. The black circles show measurements with evaporated foils, and are in good agreement with theory. The energy loss and straggling results with the rolled foils were found to be constant with position of the $\sim 2 \mathrm{~mm}$ diameter beam on the foil, a test which might suggest that the foils were uniform in thickness but did not exclude the possibility of non-uniformity on a smaller scale.

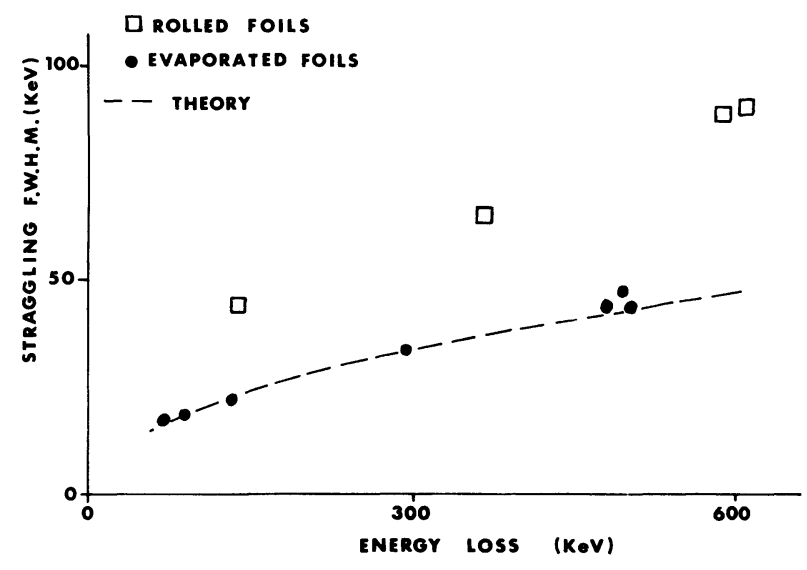

FIG. 2. - Energy straggling as a function of energy loss in various thicknesses of rolled and evaporated $\mathrm{Al}$ foils for $5.486 \mathrm{MeV} \alpha$ particles. The predictions of the Bethe-Livingston theory are also shown.

We therefore made some foil uniformity studies, using a proton beam of dimension $25 \mu \mathrm{m}$ and measuring the backscattering of $2 \mathrm{MeV}$ protons as a function of beam position along the foil. The results are shown in figure 3 . Thickness variations of the order $10 \%$ were found in the rolled foils, sufficient to explain the anomalous straggling results, whereas the evaporated foils showed uniformity to better than $1 \%$.

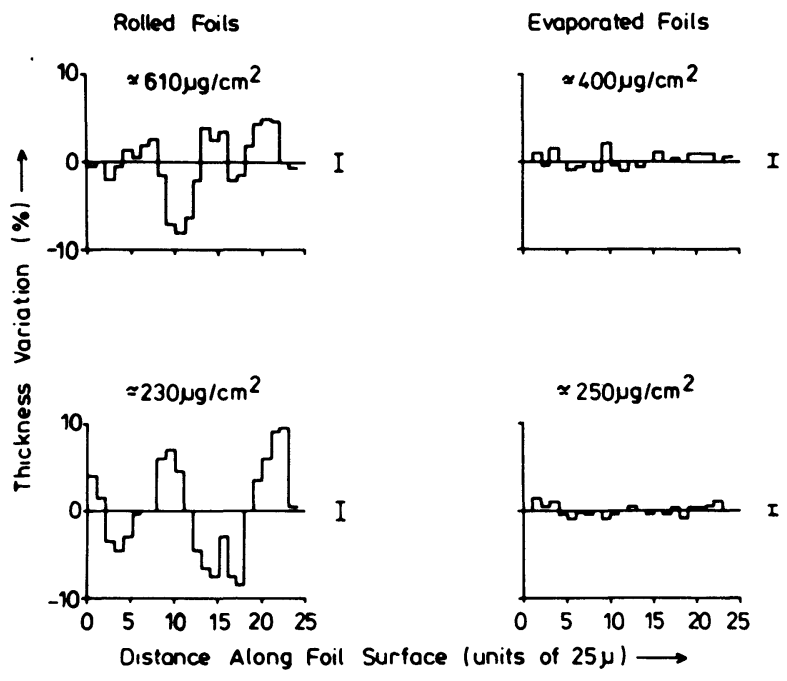

FIG. 3. - Thickness of $\mathrm{Al}$ foils, relative to the mean value, at consecutive positions. The errors associated with counting statistics in the proton back-scattering yield measurements are indicated to the right of each graph. 
To check the possibility of thickness fluctuations on a more microscopic scale in the evaporated foils, their surface topography was investigated with a Tallystep instrument equipped with a stylus of dimensions $0.1 \times 2 \mu \mathrm{m}$. Figure 4 compares the profile for $\mathrm{Al}$ of thickness $\sim 160 \mu \mathrm{g} / \mathrm{cm}^{2}$, evaporated on a clean glass slide, with that for the bare slide. Small thickness variations were thus indicated. Making use also of electron micrographs of the Al foils, we concluded that thickness fluctuations were unlikely to exceed $\pm 3 \%$ in a $160 \mu \mathrm{g} / \mathrm{cm}^{2}$ foil and were therefore within the errors of the straggling measurements.

The conclusions from this work are : (i) for fully stripped $\alpha$-particles the basic collisional straggling theory appropriate to their velocity is valid, (ii) establishment of foil uniformity requires study on a microscopic scale.
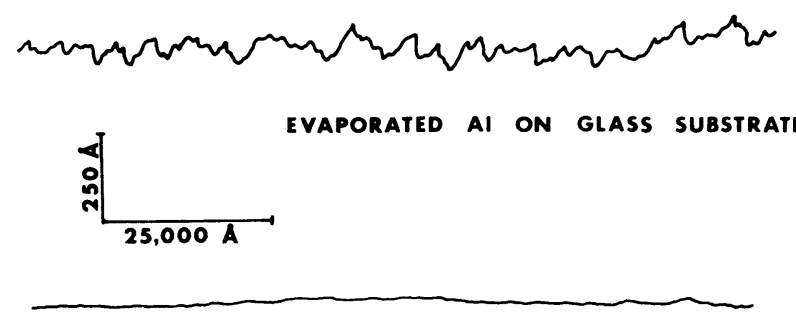

gLASS SUBSTRATE

FIG. 4. - Surface topography of Al evaporated to $160 \mu \mathrm{g} / \mathrm{cm}^{2}$ onto a glass substrate. The substrate surface topography is also shown for comparison. These traces are typical of several made at different points on the surface. Estimated visible non-uniformity is $\pm 30 \AA$ in this example.

Having verified the adequate uniformity of our evaporated $\mathrm{Al}$ foils, we were able to study the straggling of partially stripped ions.

Figure 5 shows energy loss and straggling results for $16 \mathrm{O}$ ions in the energy range 10 to $50 \mathrm{MeV}$ for three foil thicknesses. The measured straggling (open circles) is about a factor 2 greater than the theoretical prediction which takes account of fluctuations in collisional excitation only. We can therefore infer that the difference (by quadratic subtraction) between theory and experiment may be due to chargeexchange straggling. It is not possible, in general, to verify this by calculation, because charge-exchange cross sections in solids are not known. However, we chose the particular case of $40 \mathrm{MeV} 16 \mathrm{O}$ ions for which the $7^{+}$and $8^{+}$charge states were about equal and dominant. Monte Carlo calculations were made with only one variable, the cross section $\sigma_{7+\rightarrow 8+}$, assumed equal to $\sigma_{8+\rightarrow 7+}$ and the value giving the best fit to our straggling measurement was found. This turned out to be $6 \times 10^{-18} \mathrm{~cm}^{2}$ which is similar to charge-exchange cross-section measurements by Macdonald and Martin [3] for $40 \mathrm{MeV} 16 \mathrm{O}$ ions in gas targets of $\mathrm{Ar}$ and $\mathrm{N}$, i.e. 8 and $3 \times 10^{-18} \mathrm{~cm}^{2}$ respectively.
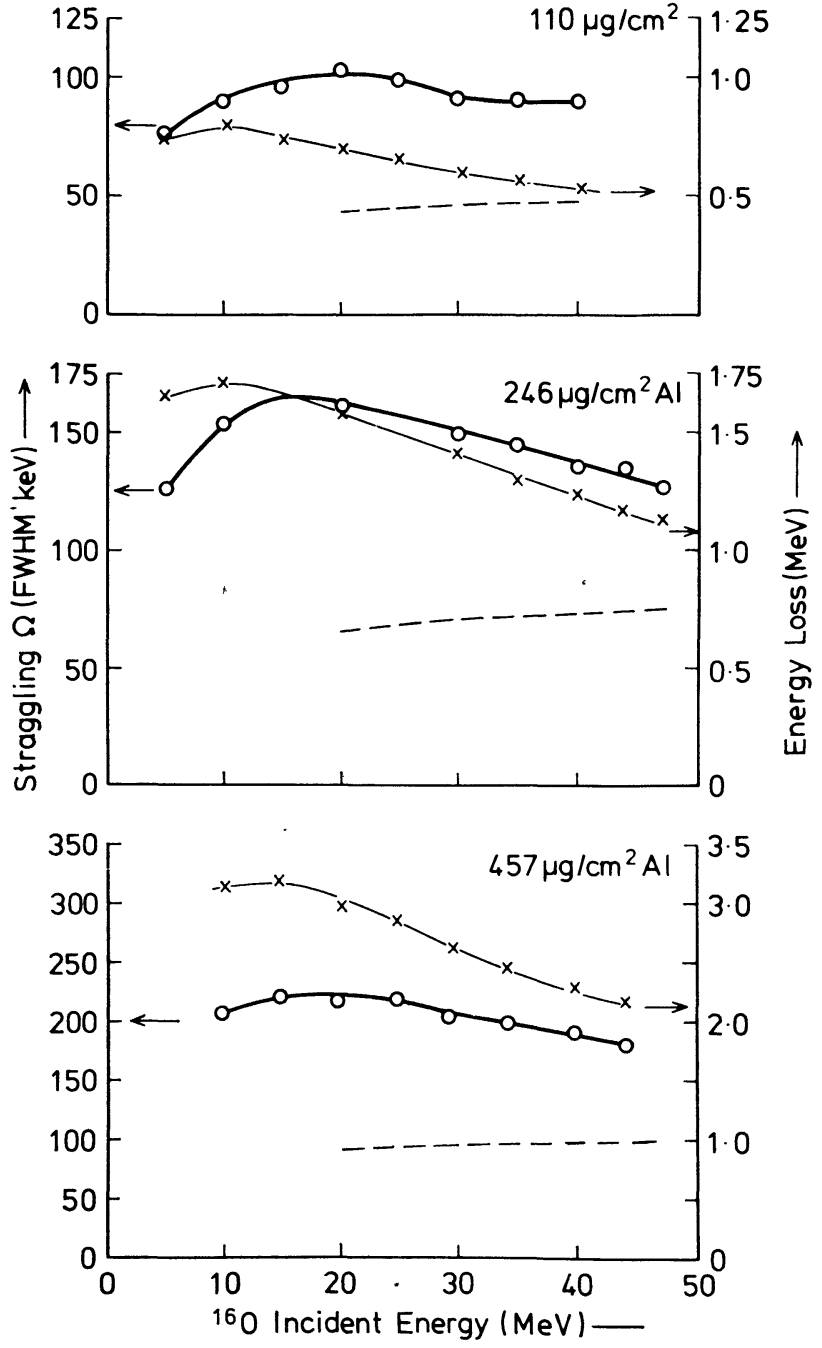

FIG. 5. - The energy loss (crosses) and energy straggling (circles) of 5 to $50 \mathrm{MeV}{ }^{16} \mathrm{O}$ ions traversing various thicknesses of $\mathrm{Al}$ foil. The theoretical predictions are shown as dashed lines.

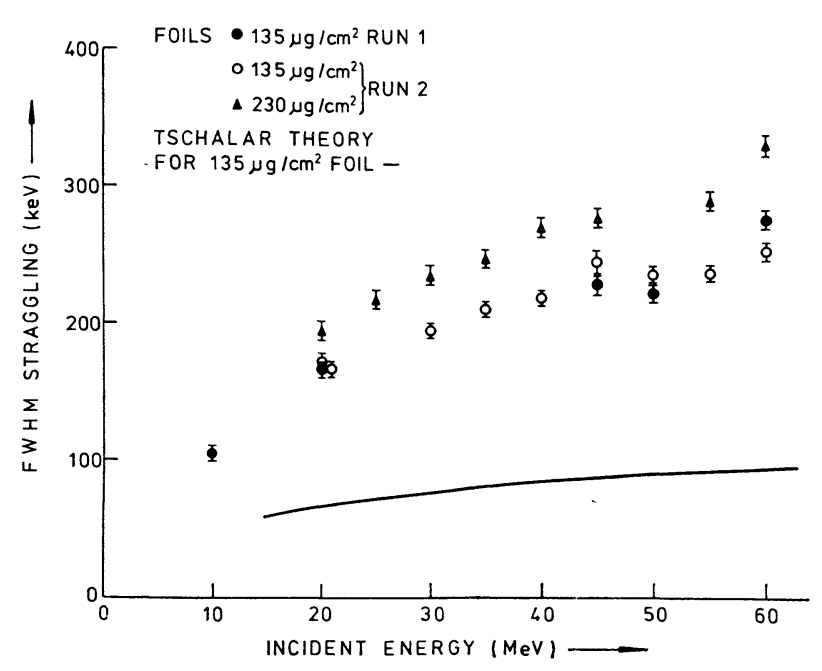

FIG. 6. - The energy straggling of $35 \mathrm{Cl}$ ions of incident energies 10 to $60 \mathrm{MeV}$ traversing two different thicknesses of $\mathrm{Al}$ foil. The curve shows the theoretical prediction for the thinner foil. 
Thus a plausible account of our observed straggling of $16 \mathrm{O}$ ions is provided.

Figure 6 shows the results we have obtained for ${ }^{35} \mathrm{Cl}$ ions in foils of two thicknesses. Again, the observed straggling exceeds by a factor of 2 or 3 that predicted from collisional theory alone. Charge-exchange effects seem likely to account for the major part of the excess.

3. Straggling in carbon stripper foils. - Using the experimentally observed fact that the straggling is proportional to the square root of the target thickness, we can predict very approximately the straggling to be expected for $16 \mathrm{O}$ and ${ }^{35} \mathrm{Cl}$ ions in an $\mathrm{Al}$ foil of thickness equivalent in energy loss to a $10 \mu \mathrm{g} / \mathrm{cm}^{2}$, say, carbon foil. These values are shown, expressed as a fraction of the energy loss, in table I, but are subject to the validity of the extrapolation to such small thicknesses. These straggling values amount to between one third and one tenth percent of the beam energy, the fractions being comparable to those found by Frick et al [4] for $48 \mathrm{MeV} \mathrm{Ni}$ ions and $110 \mathrm{MeV}$ 127 I ions.
Thus for carbon stripper foils of uniform thickness, the energy straggling does not present too serious a problem for tandem accelerators. However, if the carbon foils develop large non-uniformities during ion bombardment then the energy spread from this source could become dominant and have a significant effect on the beam resolution.

TABLE I

Extrapolation of straggling data to an Al foil of stopping power equivalent to $10 \mu \mathrm{g} / \mathrm{cm}^{2}$ carbon

\begin{tabular}{ccccc} 
& $\begin{array}{c}\text { Initial } \\
\text { energy } \\
(\mathrm{MeV})\end{array}$ & $\begin{array}{c}\text { Energy loss } \\
\text { in foil } \\
\Delta E(\mathrm{keV})\end{array}$ & $\begin{array}{c}\text { Straggling } \\
\text { FWHM } \\
\Omega(\mathrm{keV})\end{array}$ & $\begin{array}{c}\Omega / \Delta E \\
\%\end{array}$ \\
\hline $\mathrm{Ion}$ & - & - & - & - \\
$16 \mathrm{O}$ & 10 & 115 & 34 & 30 \\
$16 \mathrm{O}$ & 30 & 75 & 31 & 41 \\
$16 \mathrm{O}$ & 50 & 55 & 28 & 51 \\
$35 \mathrm{Cl}$ & 10 & 210 & 36 & 17 \\
${ }^{35} \mathrm{Cl}$ & 40 & 242 & 71 & 29 \\
${ }^{35} \mathrm{Cl}$ & 60 & 218 & 80 & 37
\end{tabular}

\section{References}

[1] Vollmer O., Nucl. Instrum. Methods 121 (1974) 373.

[2] Comfort J. R., Decker J. F., Lynk E.T., Scully M. O. and Quinton A. R., Phys. Rev. 150 (1966) 249.

Sykes D. A. and Harris S. J., Nucl. 'Instrum. Methods 101 (1972) 423.

[3] Macdonald J. R. and Martin F. W., Phys Rev. A4 (1971) 1965.

[4] Frick G., Gehringer C., Heusch B., Ricaud Ch., Wagner P. and BARON E., IEEE Trans. Nucl. Sci. NS-23 (1976) 1137. 